\title{
Real-time operational control in information management system for flash-butt welding of rails
}

\begin{abstract}
Operational control of welding quality is the fundamental element of the entire rail manufacturing process. In practice, real-time systems are used for this purpose. This article features a new method that makes use of fuzzy logic to analyze the data from mechanical tests and from the ultrasound inspection of connections.
\end{abstract}

Key words: fuzzy logic, welding, operational control

\section{INTRODUCTION}

Monitoring a product manufacturing process consists of input, operational, and acceptance control. Input control is the control of a product that reaches the consumer and is intended for use in manufacturing. The materials used for a product's manufacture have to be inspected. Operational control is the control of a product or process that is carried out during the execution of certain operations or after their completion. Acceptance inspection is the control of finished products. As a result of acceptance inspection, a decision is made on the product's conformity with the standard and suitability requirements and, ultimately, upon delivery to the consumer. The result of acceptance control is used to identify the shortcomings of the process that were not identified during operational control and to make any necessary changes.

Flash-butt welding is a multi-variable process in which one can distinguish different stages and changes of voltage, current, displacement, velocity, resistance, and energy (Fig. 1). To obtain maximum information on the nature and course of the flash-butt welding process and to study its characteristics, a constant registering of these parameters is performed at the stage of working out the flash-butt welding technology [1]. This information was used by developers to improve the process of welding but did not serve as a normative-document quality assessment. Experimentally, the welding quality dependencies were identified by changes in some welding parameters and the direct influence of these parameters on the structure change of the joint. As a result, information about the variation of any parameters may be used for a quantitative assessment of this impact.

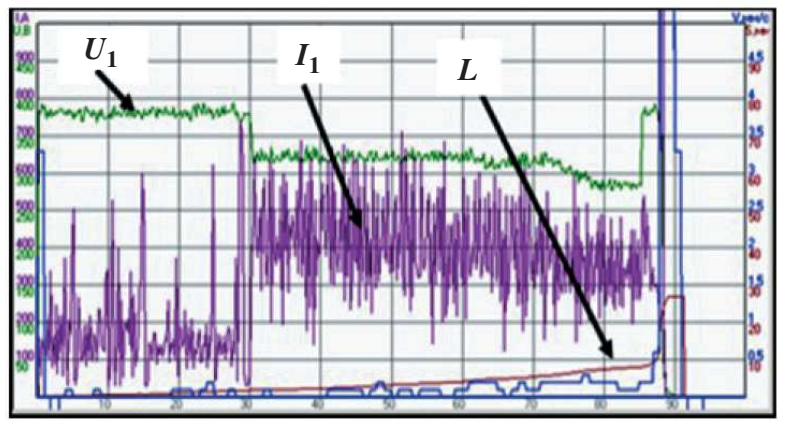

Fig. 1. Recording process of flash-butt welding of rails on K1000 machine. $U_{1}$ and $I_{1}-$ voltage and welding current at input of welding transformer; $L$ - number of movements of welded parts (melted metal sample value and upset) 
The quality of welded joints is determined by the tolerance deviations of the main parameters, which are written in the technical conditions (TC) for welded products (Tab. 1). Thus, it has become possible to carry out operational control of the registration process to compare these parameters in real time for the immediate determination of output parameters of the tolerance specifications and to reduce the probability of producing a low-quality welded whip as a whole [1].

\section{Table 1}

Tolerances on deviation of basic flash-butt welding parameters on mobile machines such as K900, K920, K922 (P65, UIC60 rails), and on stationary machine K1000 (P50, P65, P75, UIC60 rails)

\begin{tabular}{|l|c|}
\hline \multicolumn{1}{|c|}{ Welding settings } & Parameter values \\
\hline Upset pressure [MPa] & $9-12$ \\
\hline Upset speed on idling [mm/s] & not less than 20/30 \\
\hline Melting speed [mm/s] & $0.065-0.20 / 0.07-0.20$ \\
\hline Speed on melting finish [mm/s] & $0.7-2.5$ \\
\hline $\begin{array}{l}\text { Input voltage of the welding } \\
\text { transformer [V]: } \\
\text { - the first and third periods } \\
\text { - second period }\end{array}$ & $355-440$ \\
\hline Allowance for melting [mm] & $250-360$ \\
\hline Allowance for upset [mm] & $9-18$ \\
\hline
\end{tabular}

\section{JOINT INSPECTION}

Acceptance inspection of welded joints is carried out according to the ultrasonic inspection of joints and mechanical testing of rail samples (periodically during the welding whip) for compliance with the specifications (breaking load on rail foot at least $1400 \mathrm{kN}$ at a deflection of at least $30 \mathrm{~mm}$ in accordance with Ukrainian standards and, respectively, $1600 \mathrm{kN}$ and $20 \mathrm{~mm}$ in accordance with EU standards). These acceptance tests can also be used to correct the specified tolerances.

The main disadvantage of such a mode of tolerance control is that it does not take into account the following:

- the importance of the influence of individual parameters and their combinations to estimate the quality of the joint,

- the distribution of the process parameters within the tolerance,

- the blurring of the tolerance limits.

Given these, to estimate the quality conditions of weld joint specification (testing the joint breaking force and flexure value), a control algorithm based on fuzzy logic was developed. Due to the complexity of the flash-butt welding process, it was not possible to develop an analytical, statistical, or any other numerical model. The conclusion on the quality of the welded joint with a certain level of probability is based on logical rules that are made up in the study of technological features of flash-butt welding.

Here are some of these [1,2]:

- The higher the self-regulation, the higher the melting stability.

- The higher the melting stability, the lower the destruction intensity of the welding contacts.

- The lower the short-circuit impedance of welding machine $Z_{s c}$, the higher the self-regulation (higher melting stability), and melting voltage $U_{m e}$ may be decreased.

The temperature field in the welded product can be determined by the ratio of the energy released $Q$ and of the melted metal sample value $L$ (Tab. 2).

On the basis of these and similar rules, the "fuzzy" logic quality estimation rules of welded joints were developed.

To account for the blurring of the boundaries of permissible deviations of the parameters, conversion value deviations of the process parameters were used in accordance with the existing specification tolerances to a dimensionless quantity - the degree of compliance of its value according to the parameter specifications in TC. These transformation functions (which may be of different shapes) were presented in the form of a trapezium (Fig. 2). Thus, in the middle of this tolerance $X_{a v} \pm \Delta X$, where $X_{a v}$ - average value and $\Delta X=1 / 6\left(X_{\max }-X_{\min }\right)$, the membership function of the parameter specifications is equal to 1 ; then, within the tolerance limits, it decreases linearly to zero. Logical dependencies on the qualitative effect of the parameters of flash-butt welding were constructed on the basis of technology conclusions that take into account both the relative impact on the process and the location of the parameters in the tolerance zone.

Thus, welding quality assessment is carried out by an analysis of the parameters at three stages of the process: 1) melting of metal samples - the formation of a temperature field at the ends of welded products; 2) final stage of metal sample melting - providing a protective environment in the spark gap; and 3) upset - forming compounds in the solid phase. The result is determined by the degree of truth (or reliability) matching options at these stages of the specification tolerances and, consequently, the probability of obtaining a welded joint that corresponds to TC. 
Table 2

Evaluation of temperature field, depending on reproduction errors of given energy $Q$ and melted metal sample value $L$; $T F$ - temperature fields (oh - overheating, lh - low heating)

\begin{tabular}{|c|c|c|c|c|c|}
\hline$T F$ & $\begin{array}{l}\text { Large negative } \\
\text { error } L\end{array}$ & $\begin{array}{l}\text { Small negative } \\
\text { error } L\end{array}$ & Normal $L$ & $\begin{array}{l}\text { Small positive } \\
\text { error } L\end{array}$ & $\begin{array}{l}\text { Large positive } \\
\text { error } L\end{array}$ \\
\hline Large negative error $Q$ & $\operatorname{Bad} T F$ & $\begin{array}{c}\text { Bad TF } \\
\text { (lh) }\end{array}$ & $\begin{array}{l}\mathrm{Bad} T F \\
\quad \text { (lh) }\end{array}$ & $\begin{array}{c}\mathrm{Bad} T F \\
\quad(\mathrm{lh})\end{array}$ & $\begin{array}{c}\text { Bad } T F \\
\text { (lh) }\end{array}$ \\
\hline Small negative error $Q$ & $\begin{array}{c}\text { Bad } T F \\
\quad(\mathrm{oh})\end{array}$ & Normal $T F$ & $\begin{array}{c}\operatorname{Bad} T F \\
\text { (lh) }\end{array}$ & $\begin{array}{c}\operatorname{Bad} T F \\
\text { (lh) }\end{array}$ & $\begin{array}{c}\operatorname{Bad} T F \\
\quad(\mathrm{lh})\end{array}$ \\
\hline Normal $Q$ & $\begin{array}{l}\text { Bad } T F \\
\quad(\mathrm{oh})\end{array}$ & $\begin{array}{c}\text { Bad } T F \\
\quad(\mathrm{oh})\end{array}$ & Normal $T F$ & $\begin{array}{l}\operatorname{Bad} T F \\
\quad(\mathrm{lh})\end{array}$ & $\begin{array}{l}\text { Bad } T F \\
\quad(\mathrm{lh})\end{array}$ \\
\hline Small positive error $Q$ & $\begin{array}{l}\text { Bad } T F \\
\text { (oh) }\end{array}$ & $\begin{array}{l}\text { Bad } T F \\
\quad \text { (oh) }\end{array}$ & $\begin{array}{l}\text { Bad } T F \\
\text { (oh) }\end{array}$ & Normal $T F$ & $\begin{array}{l}\mathrm{Bad} T F \\
\quad \text { (lh) }\end{array}$ \\
\hline Large positive error $Q$ & $\begin{array}{l}\text { Bad } T F \\
\text { (oh) }\end{array}$ & $\begin{array}{l}\mathrm{Bad} T F \\
\text { (oh) }\end{array}$ & $\begin{array}{l}\text { Bad } T F \\
\text { (oh) }\end{array}$ & $\begin{array}{l}\mathrm{Bad} T F \\
\text { (oh) }\end{array}$ & Normal $T F$ \\
\hline
\end{tabular}
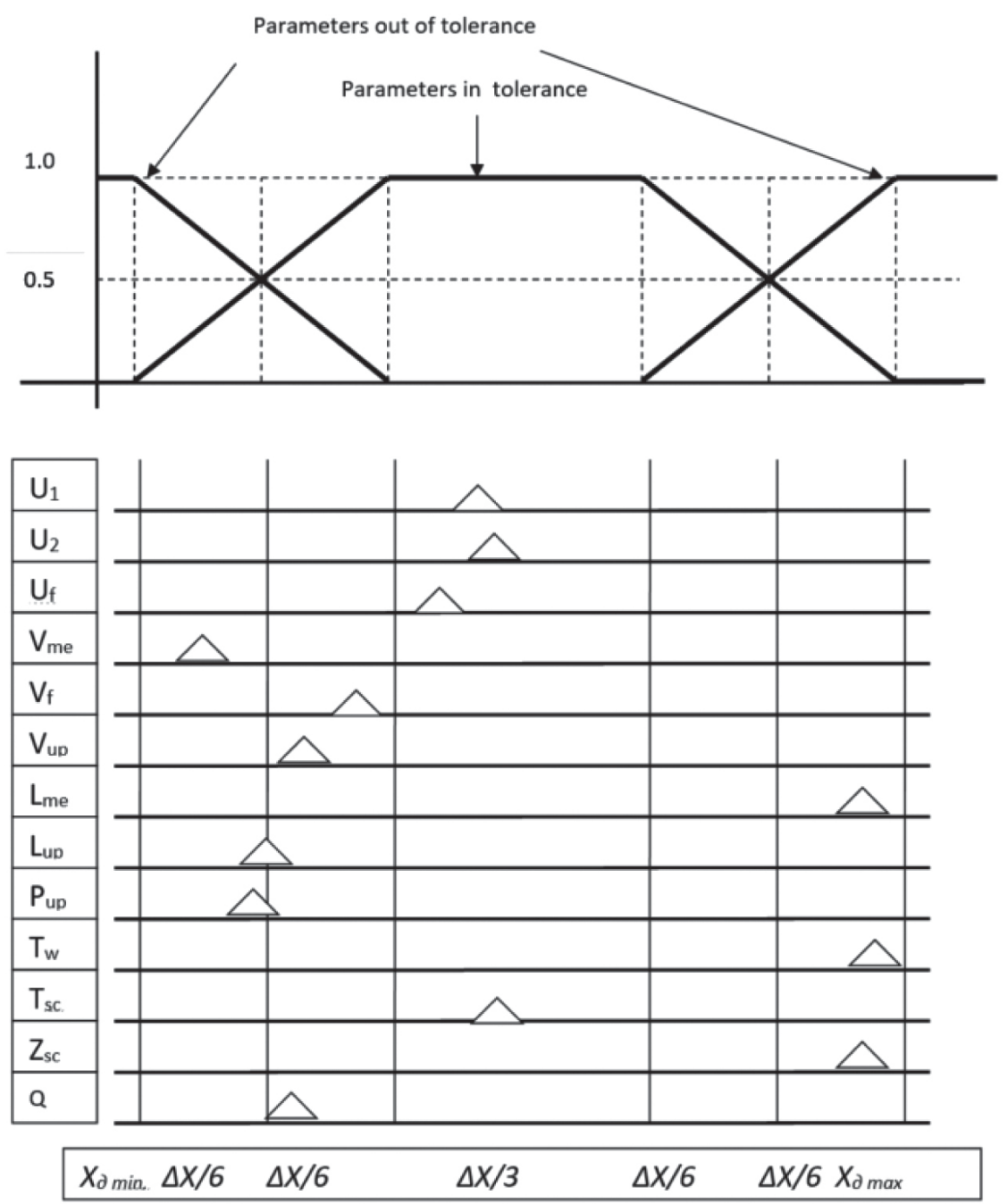

Fig. 2. Fuzzy conversion function of flash-butt welding parameters to control quality of welded joints

Further, these logical expressions have been converted by the known rules to a form that is convenient for implementation on a computer. Apart from clarifying the tolerance, the developed quality control algorithm can be updated according to the results of comparing its evaluation of data acceptance control via the adaptive fuzzy system algorithms and fuzzy neural network [4-7]. 


\section{MANAGEMENT SYSTEM}

Information about the process parameters and opinion on their compliance with the requirements of TC (in the form of a protocol on joint welding) constitute the core data of the process. These records are kept at all times during the operations of welded joints in railway lines and include significantly large amounts of information. Along with the product acceptance certificate, this information can be used to detect disturbances that impact the welding process but are not subject to direct measurement methods. Such methods of information processing (the so-called data mining) are used for the detection of previously unknown data, non-trivial, practically useful, and affordable, interpreting the knowledge necessary for decision-making in the various spheres of human activities (Wikipedia: https:// pl.wikipedia.org/wiki/Eksploracja_danych).

Using the known methods of statistical data processing on joints collected for specific periods of time on the same machine, a rail welding factory, or industry in general help us optimize the operating conditions of welding machines and production management of the welded rails.

For this purpose, a two-level information management system has been developed by the Paton Electric Welding Institute (Fig. 3) in cooperation with the Institute of Innovative Technologies (EMAG) from Katowice, Poland. On the lower level, the direct digital control system uses the traditional quality control of welded joints for the «instantaneous» response to the occurrence of marriage and prevents its further spread.

Further information about the welded joints is transmitted from the welding machine of the rail welding factories to the upper level - a diagnostic center. This diagnostic center carries out statistical processing of welding rail protocols to detect disturbances that are difficult to control by direct measurements. For example: poor performance of the auxiliary operations of rail preparation before welding; deviation from the physicochemical properties of metal rails; poor technological operation compliance of service personnel; and poor production conditions.

Apart from direct digital control of the welding process, existing local control systems have the following functions:

- welded joint quality forecasting for more-advanced algorithms with the possibility of using qualified professionals in special cases;

- monitoring the technical condition of the welding equipment and developing recommendations and maintenance planning;

- identification and recognition of emergency situations for immediate intervention in the process;

- identification of systematic deviations and trends in the welding process parameters, which may lead to a deterioration in the quality of performance of the welded joints, development of recommendations for adjusting the welding parameters.

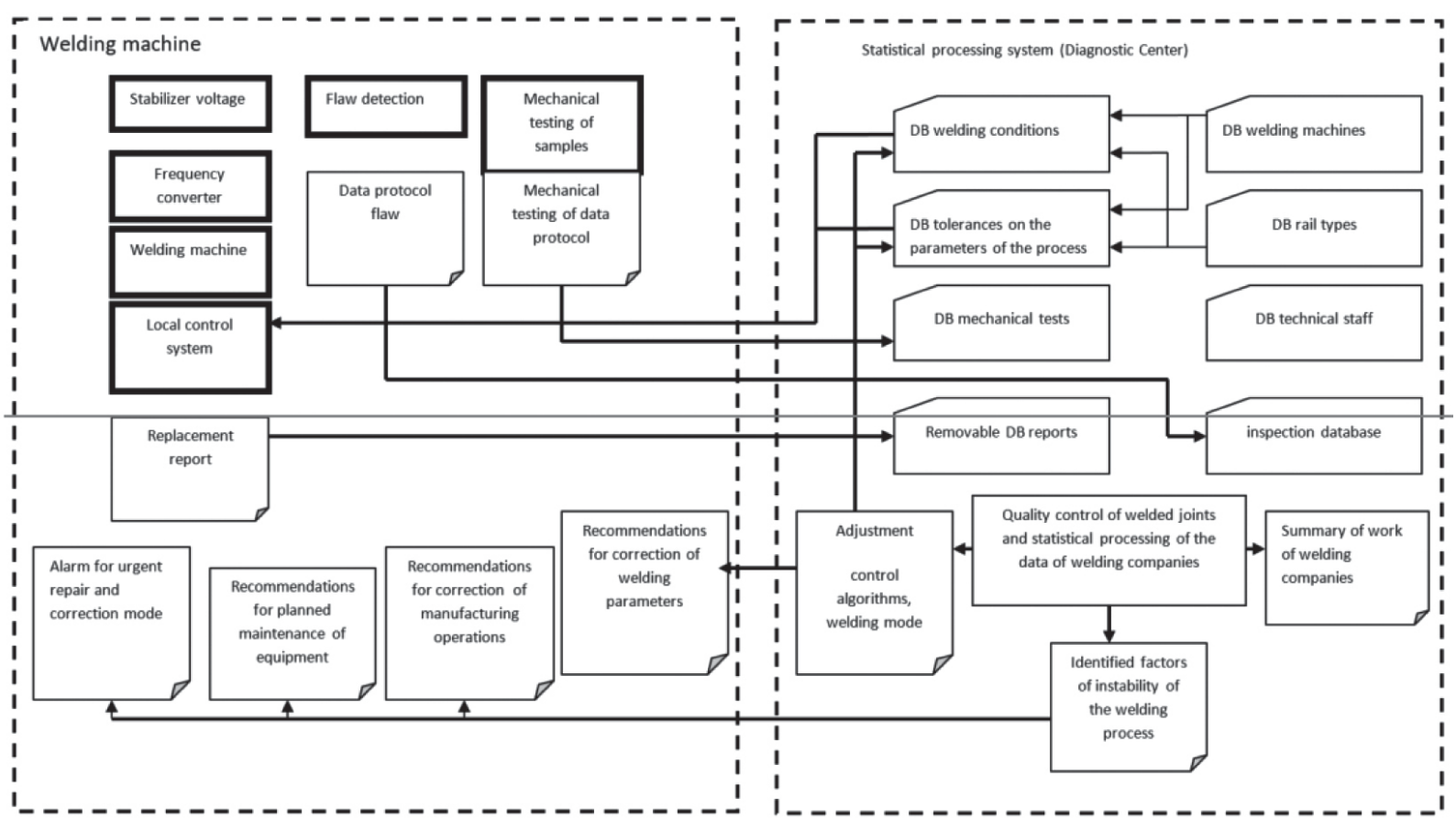

Fig. 3. Block diagram of two-level information management system 
For the flash-butt welding of rails on stationary and mobile welding machines, the following factors can lead to deviations in the production process and, as a consequence, to a violation of the quality of the welded joints $[1,2]$ :

1) poor performance of auxiliary operations on the rails before welding preparation, such as end preparation, cleaning the surface of the rails, or operations in the field of current supply and treatment of joints after welding - machining the rail surface when deburring;

2) deterioration of the technical condition of the welding equipment, such as increasing the welding machine circuit resistance;

3) defects in the rail steel-base metal;

4) poor adherence to technological operations welder (alignment of rails before welding);

5) unsatisfactory conditions of production; for example, undesirable changes of supply voltage;

6) an unfavorable combination of process parameters, even when these parameters are within tolerance limits; for example, lowering the supply voltage and increasing the circuit resistance in the welding machine.

In order to identify the described perturbations, welding joint protocol arrays are processed with the use of statistical methods as well as grouped according to relevant characteristics (Tab. 3).
During welding, the following information (Fig. 4) is generated in real time:

1) Index of the quality of the welded joint (probability of conformity with its requirement specification) is calculated after welding joints on the measured values of welding process parameters $x_{1} \ldots x_{12}$ using the control algorithm based on "fuzzy" logic [4-7]. The data on the welding machine number, names of the welder, master engineer, and the team to implement auxiliary operations (preparation of rails before welding and processing of joints after welding) are put in arrays.

2) Cracks, lack of fusion, dull spots, etc. are checked according to ultrasonic inspection for each welded joint. This data is recorded in the inspection database. Visually, the machining quality of the welded joint after deburring is also checked. Information about the presence of the above-mentioned defects as well as the possibility of a defective processing interface is immediately available to the welder and foreman. The defective joint is cut. These functions are performed outside the control of the system. Inspection data is entered manually.

3) At the beginning, middle, and end of the working day, some specimens of welded rails are tested mechanically. Test data of $L_{d e}$ deflection and breaking force $F_{b}$ are compared with predetermined values.

Table 3

Identifying violation causes of rail flash-butt welding technological process

\begin{tabular}{|c|c|c|c|c|c|}
\hline No. & $\begin{array}{c}\text { Violation cause } \\
\text { of rail flash-butt welding } \\
\text { technological process }\end{array}$ & $\begin{array}{l}\text { Parameter } \\
\text { identification }\end{array}$ & Sample size & $\begin{array}{l}\text { Parameter } \\
\text { arrays }\end{array}$ & $\begin{array}{l}\text { Parameter } \\
\text { effects }\end{array}$ \\
\hline 1 & $\begin{array}{l}\text { Auxiliary operations to prepare } \\
\text { the rail before welding and after } \\
\text { processing a welded joint }\end{array}$ & $\begin{array}{c}Z_{s c}, \text { visual data } \\
\text { processing after } \\
\text { welding the joints }\end{array}$ & $\begin{array}{l}\text { 1-2 working } \\
\text { days }\end{array}$ & $\begin{array}{l}\text { Watch master } \\
\text { name + Welding } \\
\text { factory }\end{array}$ & $\begin{array}{l}\text { Methods } \\
\text { and equipment }\end{array}$ \\
\hline 2 & $\begin{array}{c}\text { Technical condition of welding } \\
\text { equipment }\end{array}$ & $\begin{array}{l}T_{w}, U_{1}, U_{2}, V_{m e}, V_{f} \\
V_{u p}, L_{o}, L_{u p}, Z_{s c}\end{array}$ & $1 / 3-1$ month & Machine number & $\begin{array}{l}\text { Maintenance, } \\
\text { repair }\end{array}$ \\
\hline 3 & $\begin{array}{l}\text { Physico-chemical properties } \\
\text { of metal rails }\end{array}$ & $L_{d e}, F_{b}$, data inspection & $\begin{array}{l}\text { Immediately } \\
\text { upon detection } \\
\text { or } 1 \text { working day }\end{array}$ & $\begin{array}{l}\text { Lot number, mark } \\
\text { of the rail, } \\
\text { machine number }\end{array}$ & $\begin{array}{l}\text { Correction } \\
\text { of welding mode }\end{array}$ \\
\hline 4 & $\begin{array}{l}\text { Welders' technological } \\
\text { operations }\end{array}$ & $\begin{array}{l}T_{w}, T \text { between } \\
\text { the welding, } Z_{s c} \text {, delay }\end{array}$ & $\begin{array}{l}\text { Immediately } \\
\text { upon detection } \\
\text { or } 1 \text { working day }\end{array}$ & Welder's name & $\begin{array}{c}\text { Methods } \\
\text { (manufacturing } \\
\text { instructions) }\end{array}$ \\
\hline 5 & $\begin{array}{l}\text { Process control for welding } \\
\text { samples and ultrasonic inspection }\end{array}$ & $\begin{array}{l}L_{d e}, F_{b}, \text { ultrasonic } \\
\text { inspection data }\end{array}$ & 1 working day & $\begin{array}{l}\text { Welder's name, } \\
\text { Radiographer's } \\
\text { name }\end{array}$ & $\begin{array}{l}\text { Methods } \\
\text { and equipment }\end{array}$ \\
\hline 6 & Production conditions & $U_{1}, U_{2}, V_{m e}, V_{f}, V_{u p}$ & $1-2$ months & Welding factory & $\begin{array}{l}\text { Stabilization } \\
\text { of } U_{p s} \text { or } T_{o i l}\end{array}$ \\
\hline 7 & $\begin{array}{l}\text { Unfavorable combination } \\
\text { of process parameters }\end{array}$ & $\begin{array}{l}\text { Fuzzy control } \\
\text { and monitoring }\end{array}$ & $\begin{array}{l}\text { Immediately } \\
\text { upon detection } \\
\text { or } 1 \text { working day }\end{array}$ & Number of whip & $\begin{array}{c}\text { Correction } \\
\text { of welding mode }\end{array}$ \\
\hline
\end{tabular}


If the obtained values are lower than specified, additional samples are welded and tested to identify the authenticity of an unacceptable deviation. Upon confirmation of an unacceptable deviation of the process, an adjustment of welding is carried out. The obtained data is used to adjust the model welding quality control.

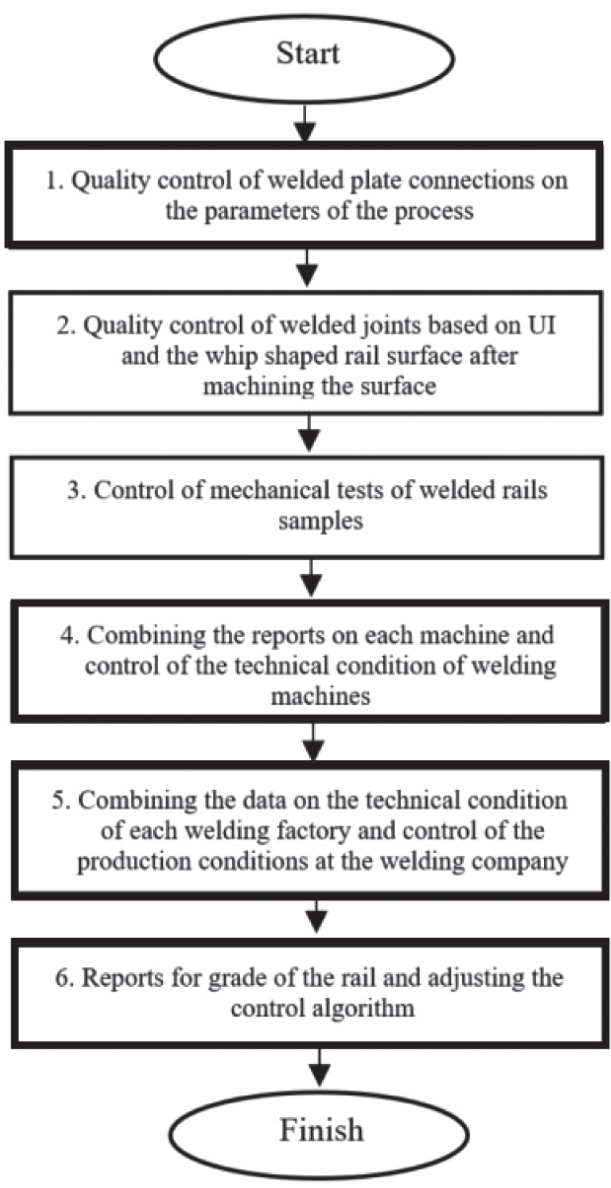

Fig. 4. Control algorithm of rail welding process.

Operations in bold-rimmed boxes are carried out in an automated mode

In the offline mode, the following information is generated:

1) To check the technical condition of the welding machine, the data of the same type of rails welded on the same machine is combined into an array of the welding machine technical condition (protocol). The reaction time (and, accordingly, the averaging time) can be significant - from one to several working days. Obviously, emergency repair information is supplied immediately.

To control the production conditions, statistical evaluations of welding on the same type of welding machines and in the same factory are combined in the data array. The stability of the power supply voltage is determined by voltage $U_{1}, U_{2}$. The stability of the hydraulic drive (which is related to the ambient temperature and its effect on the properties of the hydraulic fluid) is determined by velocity $V_{m e}, V_{f}, V_{u p}$. The comparison of these estimates at different welding factories can serve as a basis for deciding on the improvement of production conditions.

The averages and RMS of the welding parameters were used in the statistical analysis of the distribution of random values of the welding process parameters. To compare various parameters, these values were further presented in relative units - the so-called accuracy ratios $K_{a}$ and reference $K_{r}[3]$ :

$$
K_{a}=6 \cdot S / \delta ; \quad K_{r}=\left(X_{a}-X_{\hat{\imath}}\right) / \delta
$$

where:

$$
\begin{aligned}
S, X_{a}- & \text { RMS and average of parameter distribution } \\
& \text { of the welding process, } \\
\delta & - \text { the tolerance in the setting, } \\
X_{o}- & \text { the middle of the tolerance or the specified } \\
& \text { value. }
\end{aligned}
$$

To analyze the variance, it should be considered that some of the monitored parameters (e.g., $L_{m e}, U_{1}, U_{2}$, $\left.U_{3}, P_{o}, T_{u p I}\right)$ are set directly in the management system, and that errors in their operation are associated with the equipment and (in particular) the control systems.

However, other parameters $\left(V_{m e}, T_{w}, V_{f}, V_{u p}\right)$ are set indirectly. Errors of these parameters are related both to the state of the welding equipment and the progress of the process.

As an example, the system will consider the data at a ratio of accuracy of $K_{a}$ for 12 welding machines in 4 welding factories with about 30,000 welded joints.

Indirect setting of the parameters (Fig. 6) shows that three machines $(10,11,12)$ express a sharp contrast in terms of the welding-time data. These machines belong to welding factories and, of course, have been expected to show a total deviation in the characteristics of this welding businesses. An additional analysis directly in the factory has revealed differences in the applied technologies of preparing the ends of rails welded prior to welding as compared to the other welding companies.

The value of the $K_{a}$ ratio for the parameters grouped by welding factories revealed that hydraulic power stations in different welding plants (parameter $P o$ ) are different as far as their technical conditions are concerned - additional verification of this technical condition is required (Fig. 6). 


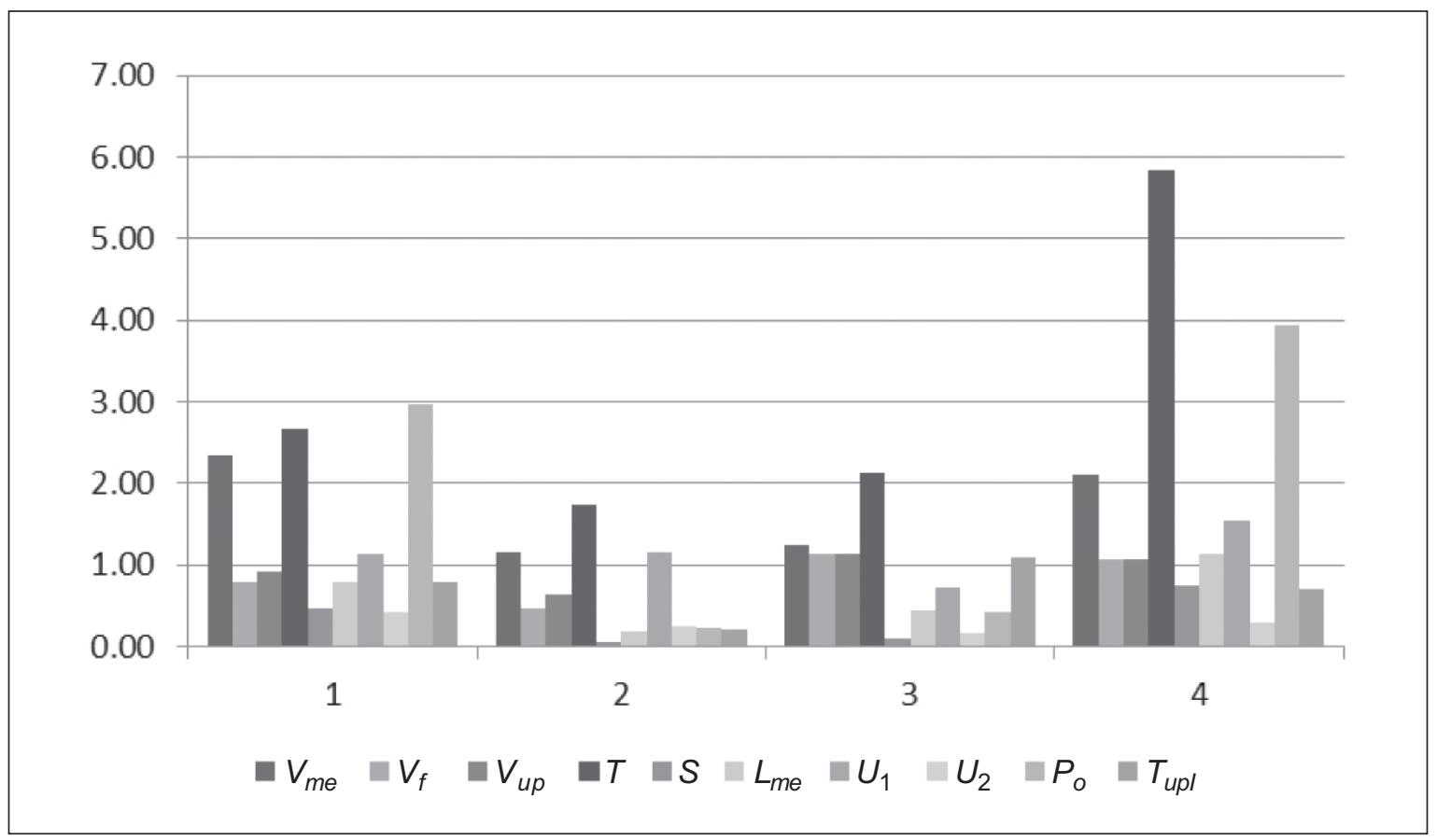

Fig. 5. The coefficients of accuracy $K_{a}$ of parameters $V_{m e}, V_{f}, V_{u p}, T_{w}$, grouped by machines

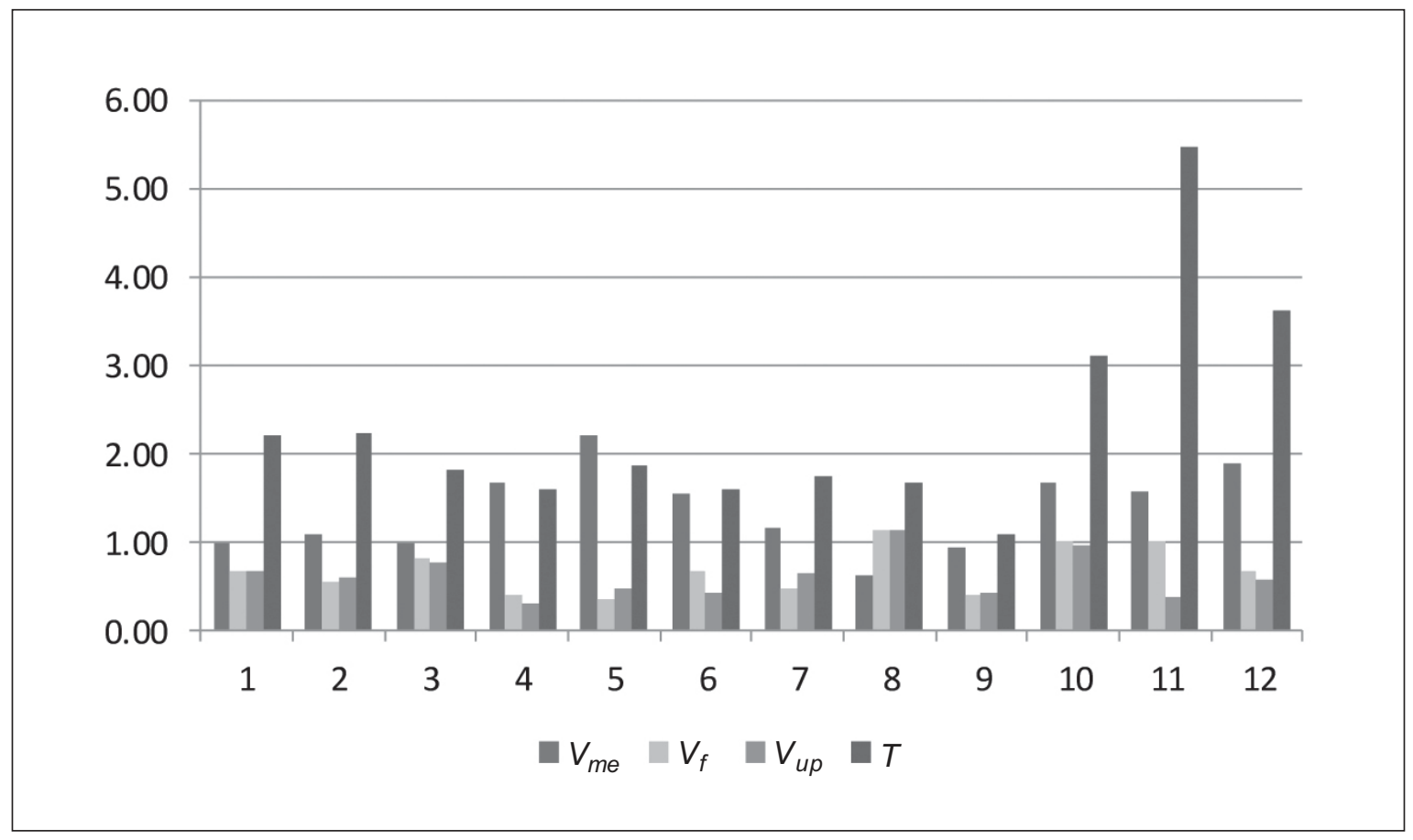

Fig. 6. Coefficients of accuracy parameters $K_{a}$, grouped by welding factory

It is obvious that, in addition to technical issues, the algorithm involves organizational issues of the production of welded tracks and not only must be updated on the experimental operation management system but primarily aligned with the direction of the service track facilities.

\section{CONCLUSIONS}

The quality control of welded joints is carried out according to the operational control, ultrasonic inspection, and mechanical testing of technological samples. 
Fuzzy logic is the basis for improving the reliability of operational control as the main means of preventing the connections in a real-time control algorithm. The control algorithm of fuzzy logic is specified according to the mechanical tests of joints and ultrasonic inspection.

A two-level information management system was developed, and a statistical analysis of the results of tolerance control of the quality of the rail joints was performed. The results revealed new opportunities for improving the quality of welded joint stability.

\section{References}

[1] Kuchuk-Yatsenko S.I.: Kontaktnaya stykovaya svarkaoplavleniyem, Naukova dumka, Kiyev 1992

[2] Gel'man A.S.: Osnovy svarki davleniyem, Mashinostroyeniye, Moskva 1970.

[3] Pustyl'nik Ye.I.: Statisticheskiye metody analiza iobrabotki nablyudeniy, Nauka, Moskva 1968.

[4] Kruglov V.V., Dli M.I.: Intellektual'nyye informatsionnyye sistemy: komp'yuternaya podderzhka sistem nechetkoy logiki $i$ nechetkogo vyvoda, Fizmatlit, Moskva 2002.

[5] Terano T., Asai K., Sueno M.: Applied Fuzzy Systems, AP Professional, London 1994.

[6] Kosko B.: Fuzzy Engineering, Prentice-Hall, Upper Saddle River 1997.
[7] Wang L.X.: A course in fuzzy systems and control, PrenticeHall, Upper Saddle River 1997.

[8] Wojtas P., Kozłowski A.: Innowacyjne rozwiazania CNP $E M A G$, Sympozjum SEMAG: Elektroenergetyka i automatyka w przemyśle wydobywczym, Szklarska Poręba 2013.

SERGEI IVANOWICH KUCHUK-YATSENKO
PIOTR MIKHAILOVICH RUDENKO
VALERY SEMIONOVICH GAVRYSH
ALEXANDR VLADIMIROVICH DIDKOVSKY
VALENTINA IVANOVNA SHVETS
EVGENI VALENTINOVICH ANTIPIN

The E. O. Paton Electric Welding Institute of the NAS of Ukraine, Kazimir Malevich St 11, Kiev, 03680, Ukraine office@paton.kiev.ua

PIOTR WOJTAS, Ph.D., Eng. KZESO MACHINERY Ltd. of Poland ul. Karoliny 4, 40-186 Katowice, Poland piotr.wojtas@kzeso.pl

ARTUR KOZŁOWSKI, Ph.D., Eng. Institute of Innovative Technologies EMAG ul. Leopolda 31, 40-189 Katowice, Poland A.Koztowski@ibemag.pl 